\title{
A Three-Dimensional Lump Model on Performances of the Stapes Displacement under Different Mechanics Property Conditions of a Middle Ear
}

\author{
Yi-Chern Hsieh and Doan Minh Hai \\ Department of Power Mechanical Engineering, National Formosa University, Yunlin 63208, Taiwan.
}

\author{
Yue-Lin Hsieh \\ Department of Otorhinolaryngology, Eye Ear Nose and Throat Hospital of Fudan University, Shanghai, China.
}

(Received 30 July 2018; accepted 26 April 2019)

\begin{abstract}
In this article, a three-dimensional (3D) lumped model of the human auditoria peripherals that consisted of four masses equipped with five major springs and major dashpots is presented. This model will support the quantitative basis for construction of a human middle ear physical model. This 3D lumped model consists of a human ear bone model having a similar working principle as the tiny mechanical structure. The 3D lumped model's parameters were identified using previous anatomical data, and then constructed via a parameter optimizing process using 16 springs and dashpots that represent the tiny mechanical structure's five connections. The computational results showed the sensitivity priority of the five connections to the stapes displacement with a variety of sound frequencies. Moreover, a detailed discussion of the five connections' mechanical properties affecting the magnitude of the stapes displacement was also shown in this paper. As a result of increasing the stiffness in the joint of the middle ear bone connection, the stapes' vibrational amplitude was increased. However, the magnitude of the value of the four masses reacts in a manner that is opposite to stapes displacement. Some specific frequency ranges of the voice properties to the mass and connector systems are also discussed in this paper. The details of the individual mass or joint activity to the stapes displacement at various frequency ranges are also presented. The model's behaviors were calculated using the software ANSYS workbench 15.0, Solid works 2017, and the MATLAB R2015a. Our findings provide a relevant reference for related medical research.
\end{abstract}

\section{INTRODUCTION}

The anatomical structures of air conduction (AC) sound transmission system in the human middle ear include the tympanic membrane (TM), three ossicles (stapes, incus, and malleus), and the middle ear cavity associated with muscle systems that are equivalent to a mechanical structure combined with springs and dampers. Sound transmission can be interrupted to a certain degree by the anatomical and histological variations in the ossicular chain. Sound transmission via the middle ear bones can be severely affected by diseases, such as otosclerosis and otitis media. All of the experiments concerning the middle ear bone-associated sound transmission have been done in human ear bones. Functional simulation models have successfully replicated traditional mechanical sounds in normal and pathological states by modifying the parametrically flexible model. Many models having been used in implant and prosthetic development, including the model parameters, ${ }^{1-3}$ numerical finite element models, ${ }^{4}$ and physical models. ${ }^{5}$ The parameter model is one of the preliminary quantitative methods for simplifying the transfer of vibrations from the eardrum via the middle human ear bones to the inner ear. ${ }^{2,3,6,7}$ During the past few decades, the development of computer technology has been used to demonstrate not only material properties, but also the detailed geometrical information of the ear system. The middle ear bones' function analyzed by using precisely finite element models have recently been reported by Gan et al. and Meister et al., ${ }^{4,8}$ However, the finite element model is incapable of confirming the experimental measurements from the real equipment, but that type of measurement can be illustrated directly using the three-dimensional (3D) lumped model illustrated as a mesh model.

The circuit model used in the engineering approach is capable of promoting the development of a theoretical basis for building physical models. ${ }^{10}$ In order to simplify complex system modeling with a limited degree of freedom requires both optimal sensitivity and parametric studies. The outcomes include advantages when building and adjusting the physical model parameters. Early works on the middle ear have established a circuit model. ${ }^{2,6}$ In this study, we designed a middle ear bone simulator and suggested a four-mass combined model of the human auditoria peripherals. The model consists of four masses suspend by five major springs, and five major dashpots simulating the mechanical sound mechanical connection from the external ear canal through the middle ear bones to the inner ear. The values of the 3D lumped model, which were determined in the experiment, were compared with the other studies' experimental results. 


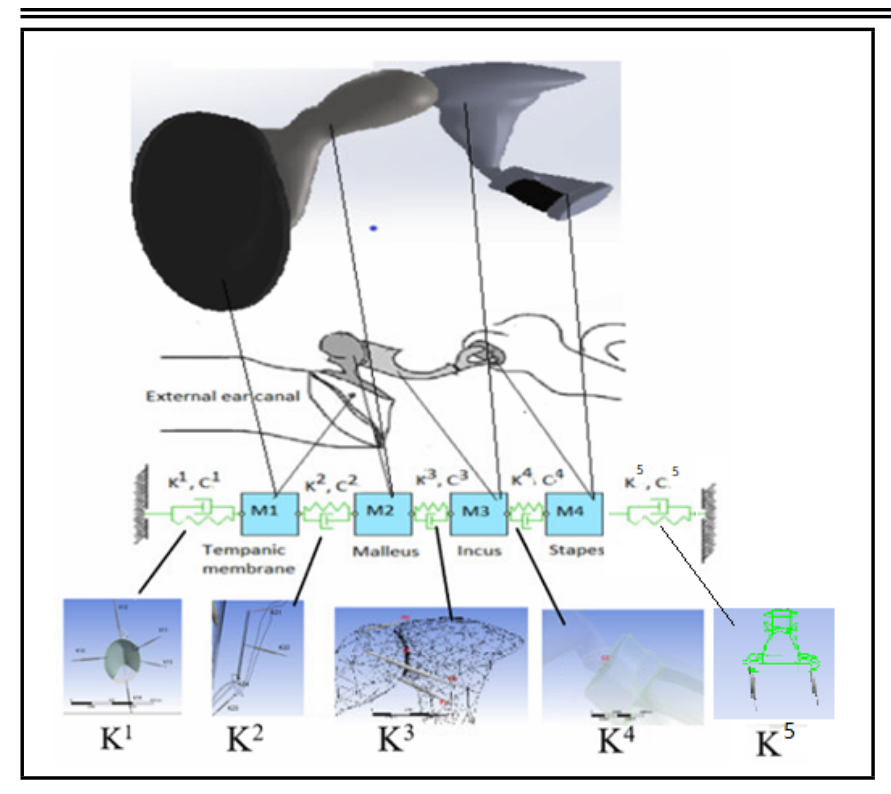

Figure 1. The parametric model of the human ear.

\section{RESEARCH METHODS}

The middle ear muscles contract rapidly with the small joints during sound transmission. In this study, the tiny muscle structure was replaced with a tiny mechanical structure, and the small connector joints in the middle ear was replaced with a tiny spring and dashpot. The computational model, consisting of four masses connected by springs and dashpots to simulation of the human middle ear bones, includes the external ear canal, TM, malleus, incus, stapes, and cochlea as shown in Fig. 1. In this diagram, the joints between the malleus and incus and the incus-stapes (M-I and I-S, respectively), which connect the three ear bones (malleus, incus, and stapes), are represented by two major springs and dashpots: $\mathrm{K}^{3}, \mathrm{C}^{3}$ and $\mathrm{K}^{4}$, $\mathrm{C}^{4}$. The malleus $\left(\mathrm{M}_{2}\right)$ is attached to the $\mathrm{TM}\left(\mathrm{M}_{1}\right)$ through $\mathrm{K}^{2}$ and $\mathrm{C}^{2}$. Ligaments are located in the middle ear, and the intramural muscles support the ossicles. Attachment of the stapes footplate to the cochlea is represented by the small spring $\left(\mathrm{K}^{5}\right)$ and dashpot $\left(\mathrm{C}^{5}\right)$, and the TM connection with the external ear canal is represented by $\mathrm{K}^{1}$ and $\mathrm{C}^{1}$. At the first connection of $\mathrm{K}^{1}$ and $\mathrm{C}^{1}$, we constructed five springs and five dashpots from $K_{1}^{1}$ to $K_{5}^{1}$ and $C_{1}^{1}$ to $C_{5}^{1}$. The second connection was located between the TM and malleus. The M-I has four springs and dashpots, whereas the I-S has only one spring and dashpot. The last connection between the stapes and cochlea consists of two springs and dashpots, $\mathrm{K}^{5}$ and $\mathrm{C}^{5}$. In this study, all of the boundaries between sections follow those from earlier studies by Sun et al. and Volandri et al. ${ }^{11,12}$ The mass of each of the ear bones was increased by $4.17 \%$ to $8.33 \%$ to $12.5 \%$ to $16.7 \%$ to $25 \%$ and finally to $41.7 \%$, and the mass-associated effects on the ear bones' vibrations within the ear bone system were examined.

The governing equations of the tiny vibration mechanical structure are shown in the equation:

$$
[\mathbf{M}][\ddot{\mathbf{Y}}]+[\mathbf{C}][\dot{\mathbf{Y}}]+[\mathbf{K}][\mathbf{Y}]=[\mathbf{F}]
$$

in which $[\boldsymbol{M}](4 \times 4)$ was the mass matrix, $[\mathbf{C}](4 \times 4)$ was the damping matrix of the four connections, $[K](4 \times 4)$ was the stiffness matrix of four connections, $[\mathbf{Y}](4 \times 1)$ was the dis- placement matrix, and $[\boldsymbol{F}](4 \times 1)$ was the force matrix that includes the external forces acting on each ear bone, the acceleration matrix $[\ddot{\mathbf{Y}}](4 \times 1)$, and the velocity matrix $[\dot{\mathbf{Y}}]$ in this model.

$$
\begin{aligned}
& {[M]=\left[\begin{array}{llll}
M_{1} & & & \\
& M_{2} & & \\
& & M_{3} & \\
& & & M_{4}
\end{array}\right]} \\
& {[C]=\left[\begin{array}{cccc}
C^{1} & -C^{1} & \multicolumn{2}{c}{-C^{2}} \\
-C^{1} & C^{1}+C^{2} & \multicolumn{2}{c}{} \\
& -C^{2} & C^{2}+C^{3} & -C^{3} \\
& & -C^{3} & C^{4}+C^{5}
\end{array}\right]} \\
& {[K]=\left[\begin{array}{cccc}
K^{1} & -K^{1} & \multicolumn{2}{c}{-K^{2}} \\
-K^{1} & K^{1}+K^{2} & \multicolumn{2}{c}{} \\
& -K^{2} & K^{2}+K^{3} & -K^{3} \\
& & -K^{3} & K^{4}+K^{5}
\end{array}\right]} \\
& \begin{array}{l}
{[Y]=\left[\begin{array}{llll}
Y_{1} & Y_{2} & Y_{3} & Y_{4}
\end{array}\right]^{T}} \\
{[F]=\left[\begin{array}{llll}
F_{1} & F_{2} & F_{3} & F_{4}
\end{array}\right]^{T}}
\end{array}
\end{aligned}
$$

In this study, $K_{j}^{i}$, $C_{j}^{i}: \mathrm{i}$ is the number of connections, and $\mathrm{j}$ is the spring number of each $i$.

The proposed ear bone model is one of the mechanical systems with four degrees of freedom consisting of four masses $\left(\mathrm{M}_{1}-\mathrm{M}_{4}\right)$, a major spring system $\mathrm{K}^{\mathrm{i}}\left(\mathrm{K}^{1}-\mathrm{K}^{5}\right)$ that replaced the small connector joints, and the dashpot system $\mathrm{C}^{\mathrm{i}}\left(\mathrm{C}^{1}-\mathrm{C}^{5}\right)$. In this system, $\mathrm{K}^{1}, \mathrm{C}^{1}$ was the contact point of the TM with the external ear canal, and $\mathrm{K}^{2}, \mathrm{C}^{2}$ was the contact point of the TM and malleus. $\mathrm{K}^{3}, \mathrm{C}^{3}$ and $\mathrm{K}^{4}, \mathrm{C}^{4}$ were the contacts of the two bones, the $\mathrm{M}-\mathrm{I}$ and $\mathrm{I}-\mathrm{S}$, and $\mathrm{K}^{5}, \mathrm{C}^{5}$ was the connection between the stapes and cochlea.

$$
\begin{array}{r}
\frac{1}{K^{i}}=\frac{1}{K^{i_{1}}}+\frac{1}{K^{i_{2}}}+\ldots+\frac{1}{K^{i}{ }_{n}} \\
C^{i}=\sum_{j=1}^{n} C_{j}^{i}=C_{1}^{i}+C_{2}^{i}+\ldots \ldots+C_{j}^{i}
\end{array}
$$

The TM has a surface area ranging from 55.8 to $85.0 \mathrm{~mm}^{2}, 13,14$ with a mean thickness ranging from 0.045 to $0.1 \mathrm{~mm}$, and the density of the TM is $1200 \mathrm{~kg} / \mathrm{m}^{3} \cdot{ }^{15-18}$ The TM had a mass ranging from 3 to $10.2 \mathrm{mg}$. The malleus and incus bones were considered as solid body vibrations at the frequencies ranging from 250 to $10,000 \mathrm{~Hz} .{ }^{4,9,15,19,20}$ The numerical result of the ear bones' amplitude vibration was $<0.01 \%$ of the length of the malleus and incus bones. The experimental impact on the human ear bones indicated that cochlear impedance's dominance decreased at frequencies between 500 and $5000 \mathrm{~Hz}$, whereas the intensities increased, and the phase exceeded 5 $\mathrm{kHz}$. These results demonstrated that cochlear resistance is dominant at low frequencies in which the response impedance ought to be thought of as frequencies $>5000 \mathrm{~Hz}$.

Table 1 shows the first parameter from the Kringlebotn ${ }^{3}$ model in which the stapes displacement was compared with experimental data from the human ear bones. Based on the optimization parameter values, replacing each spring's stiffness led to different outcomes. The next joint was the I-S, 


Table 1. All first parameters from the the Kringlebotn model.
\begin{tabular}{|l|l|l|l||}
\hline \hline Spring & Values (N/m) & $\begin{array}{l}\text { Dashpot } \\
\text { coefficient }\end{array}$ & $\begin{array}{l}\text { Values } \\
\text { (N.s/m) }\end{array}$ \\
\hline $\mathbf{K}^{\mathbf{1}}$ & & $\mathrm{C}^{1}$ & 0.0072 \\
$\mathbf{K}^{\mathbf{2}}$ & 1200 & $\mathrm{C}^{2}$ & 0.0432 \\
$\mathbf{K}^{\mathbf{3}}$ & 947.4 & $\mathrm{C}^{3}$ & 0.0036 \\
$\mathbf{K}^{\mathbf{4}}$ & 1000000 & $\mathrm{C}^{4}$ & 2.16 \\
$\mathbf{K}^{\mathbf{5}}$ & 1200 & $\mathrm{C}^{5}$ & 0.054 \\
\hline
\end{tabular}

Table 2. Initial values of mass input to model.

\begin{tabular}{||l|l|l|l||}
\hline Rigid body & $\begin{array}{l}\text { Density }\left(\mathrm{kg} / \mathrm{m}^{3}\right) \\
\text { R.Z. Gan }(2006)^{25}\end{array}$ & $\begin{array}{l}\text { Calculate } \\
\text { mass }(\mathrm{mg})\end{array}$ & $\begin{array}{l}\text { Volume } \\
\left(\mathrm{mm}^{3}\right)\end{array}$ \\
\hline TM pars tensa & 1200 & 8.79 & 3.9738 \\
TM pars flaccida & 1200 & 2.21 & 0.95686 \\
Malleus & 2550 & 54 & 21.004 \\
Incus & 2360 & 42.8 & 18.142 \\
Stapes & $2200($ Lee $)$ & 9.72 & 4.419 \\
\hline
\end{tabular}

which used only one spring and had a stiffness of $1050 \mathrm{~N} / \mathrm{m}$. The dumping of the dashpot was $2.16 \mathrm{Ns} / \mathrm{m}$, and the last ligament used two springs and dashpot in order to preserve the connection from the stapes to the cochlea. ${ }^{19}$ In Table 2, the data was converted from Gan's (2006) ${ }^{21}$ model. We derived the stapes displacement, $\mathrm{M}_{4}$, and compared these results with human ear bone experimental data. Obvious differences between the model predictions based on the initial values in Table 2 and experimental stapes displacement data exists. This approach is the first to provide values for this parameter's enhancement. Based on the optimimal parameter values, we chose the parameter values that underwent a dramatic change based on the mass of each bone.

\section{VALIDATION OF THE MODEL}

To confirm that the 3D lumped middle-ear model would offer satisfactory predictions, comparisons with three experimental studies were undertaken. Experimental displacements of the auditory ossicle displacement based on studies by from Gan et al. ${ }^{18-21}$ were initially chosen for model verification. Once the instantaneous sound pressure level input to the TM was $90 \mathrm{~dB}$, a concomitant pressure of $0.632 \mathrm{~Pa}$ was delivered close to the eardrum, and the displacement of the stapes footplate was measured. Under similar instantaneous sound pressures that were applied on the lateral side of the TM in our 3D lumped model, the magnitude of the stapes displacement was also calculated. The measurements are illustrated in Fig. 2. The pattern, and therefore the trend in the frequency response shown in the curve, as predicted by our 3D lumped model, was similar to the mean experimental curve. Aibara et al. ${ }^{22}$ used an optical Doppler measuring device to accumulate the transfer function of the stapes velocity, which demonstrated the ear's sound transmission property from the 11 fresh bones. ${ }^{23,26}$ For comparison, an identical pressure of $90 \mathrm{~dB}$ on the lateral side of the TM was applied to the 3D lumped model. An analysis was conducted on the model across frequencies varying from 250 to $10,000 \mathrm{~Hz}$.

Experimental results from the stapes displacement experiments published by Feng et al., ${ }^{1} \mathrm{Gan},{ }^{4}$ and $\mathrm{Liu}^{23}$ were also selected for model evaluation. With a uniform harmonic pressure stimulus of $90 \mathrm{~dB}$, SPL was applied to the lateral side of the eardrum in the middle ear 3D lumped model, and a harmonic analysis was conducted across the frequency ranges of

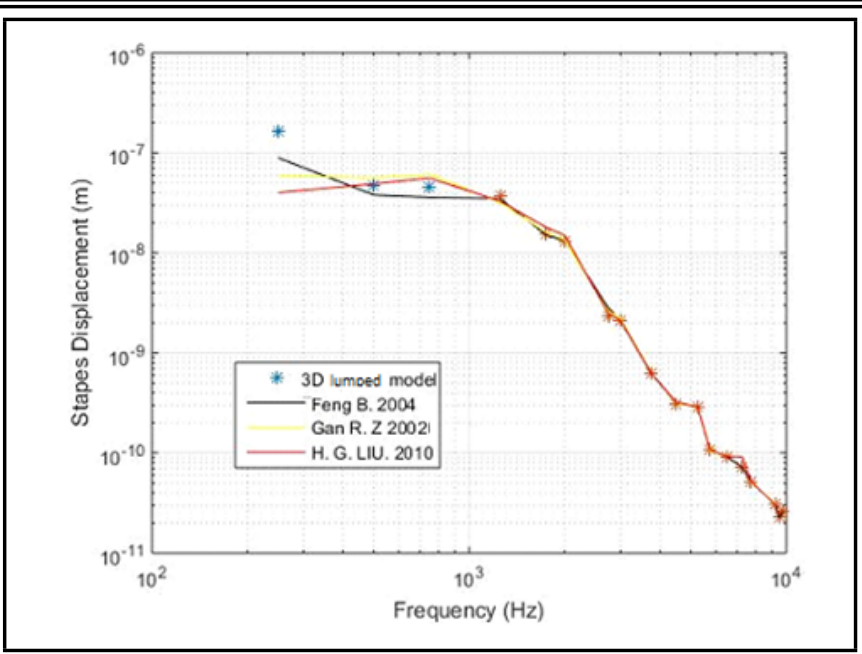

Figure 2. Stapes displacement predicted by the 3-D lumped model and other experimental results.

20 to $10,000 \mathrm{~Hz}$. Fig. 2 shows the stapes displacement magnitude predicted by our 3D lumped model (red line) as compared with the published data from Feng et al., ${ }^{1}$ Gan, ${ }^{4}$ and Liu. ${ }^{23}$ All comparisons with the experimental data were measured in the human temporal bones or the human subjects (as shown in Fig. 2) and revealed that the lumped model worked effectively at predicting the middle ear mechanical sound transmission. When comparing this model with other previous model, the present lumped model provides more accurate predictions concerning the middle ear's transfer function. These figures demonstrate that the predictions of our middle-ear 3D lumped model generally match the experimental results obtained from a human ear. Therefore, the middle-ear 3D lumped model is capable of predicting biomechanical characteristics of the human middle ear system. The calculated outcome of the final parameter values were also included in the material properties of the ear bone. ${ }^{15}$ The final values of the 3D lumped model yielded valuable simulation results with the effects of the TM, I-S, and stapes displacement in the middle ear. Therefore, the proposed 3D lumped model in this paper was aimed at physiological and mathematical concerns.

\section{RESULTS}

The 3D lumped model was constructed based on published anatomical results and physical bone experimental outcomes. The data model representing the connection of ear bone and boundary conditions are shown in Table 3 . In order to make an outstanding contribution to each parameter in this model, we calculated the curves of the stapes displacements' frequency responses $\left(\mathrm{M}_{4}\right)$ when the values parameters were increased or decreased 10 times. Final optimization values are shown in Table 3 . The last picture reveals that 16 parameters belong to the five joints of the ear bone: (1) connection of the TM membrane and external ear canal $\left(\mathrm{K}^{1}\right)$; contact of the $\mathrm{TM}$ and malleus $\left(\mathrm{K}^{2}\right)$; contact of the malleus and the incus $\left(\mathrm{K}^{3}\right)$; contact of the incus and the stapes $\left(\mathrm{K}^{4}\right)$; and the attachment of the stapes to the cochlea $\left(\mathrm{K}^{5}\right)$. These parameters are a key influence on the vibration transmission behavior of this model. 


\section{Effect of $\mathrm{K}^{\mathbf{1}}$ (stiffness of connective between tym- panic membrane (TM)-external ear canal) on the model}

$\mathrm{K}^{1}$ connected via five springs and five dashpots within the 3D lumped model had an effect on stiffness. The original parameters and mass $\mathrm{M}_{4}$ displacement results are computed in Fig. 3.

The line chart illustrates that once the annulus stiffness $\mathrm{K}^{1}$ increased 10 times, $\mathrm{M}_{4}$ 's auditory ossicle displacement had a pronounced rise within the frequency from 1000 to $2800 \mathrm{~Hz}$, and at higher frequencies ( $\mathrm{f}>5000 \mathrm{~Hz}$ ), as shown in Fig. $3 b$, the displacement of $\mathrm{M}_{4}$ varies by an unstable trends in the different springs' binding sites, indicating that each of the positions on the TM has different effects on hearing that lead to different pathologies for the human ear. Fig. 3a had almost the same result as Fig. $3 \mathrm{~b}$ with just a displacement increase at frequencies ranging from 2800 to $5000 \mathrm{~Hz}$. The relationship of the TM's stiffness to the stapes displacement $\left(\mathrm{M}_{4}\right)$ from the 3D lumped model was in agreement with the stiffness effects connected with TM changes in the pathological state previously revealed by the physical, ${ }^{5}$ the finite element $1,{ }^{4,11,26-28}$ and lumped models. ${ }^{1,17}$ This finding demonstrated that the proposed 3D lumped model is capable of playing a vital role in predicting the effects of TM vibrations on the middle ear.

\section{The Effects of $\mathrm{K}^{2}$ (stiffness connect of tympanic membrane-malleus) on the model}

The effects of $\mathrm{K}^{2}$ are shown in Figs. $4 \mathrm{a}$, and $4 \mathrm{~b}$. The results underwent a dramatic change in spring stiffness at different positions, and the stapes' oscillations were also proportional to that increase or decrease. The displacement decreases at frequencies from $250 \mathrm{~Hz}$ to $2000 \mathrm{~Hz}$. At frequencies ranging from 2800 to $3000 \mathrm{~Hz}$, there was a difference with a 10-time increase in the spring stiffness; the stapes oscillation almost increased while decreasing the springs tenfold in two of the four springs that make up the difference in the motion on the stapes.

From Fig. 5, it can be seen that, by increasing or decreasing the value of the stiffness, $\mathrm{K}^{3}$ was not much of an influence on the displacement of $\mathrm{M}_{4} . \mathrm{K}^{3}$ had a slight effect on $\mathrm{M}_{4}$ at

Table 3. The final result of the parameters.

\begin{tabular}{|c|c|c|c|c|c|}
\hline $\begin{array}{l}\text { Spring } \\
\text { parameter }\end{array}$ & $\begin{array}{l}\text { Initial } \\
\text { values }\end{array}$ & $\begin{array}{l}\text { Spring } \\
\text { param- } \\
\text { eter } \\
\text { element }\end{array}$ & $\begin{array}{l}\text { Initial } \\
\text { values } \\
\text { element }\end{array}$ & $\begin{array}{l}\text { Final } \\
\text { element } \\
\text { values after } \\
\text { optimization }\end{array}$ & $\begin{array}{l}\text { Final values } \\
\text { after } \\
\text { optimization }\end{array}$ \\
\hline $\mathrm{K}^{1}$ & 1200 & $\begin{array}{l}K_{1}^{1} \\
K_{2}^{1} \\
K_{3}^{1} \\
K_{4}^{1} \\
K_{5}^{1}\end{array}$ & $\begin{array}{l}6000 \\
6000 \\
6000 \\
6000 \\
6000\end{array}$ & $\begin{array}{l}5875 \\
5875 \\
5875 \\
5875 \\
5875\end{array}$ & 1175 \\
\hline $\mathrm{K}^{2}$ & 947.4 & $\begin{array}{l}K_{1}^{2} \\
K_{2}^{2} \\
K_{3}^{2} \\
K_{4}^{2}\end{array}$ & $\begin{array}{l}3789.6 \\
3789.6 \\
3789.6 \\
3789.6\end{array}$ & $\begin{array}{l}9470 \\
9470 \\
9470 \\
9470\end{array}$ & 2367.5 \\
\hline $\mathrm{K}^{3}$ & 1000000 & $\begin{array}{l}K_{1}^{3} \\
K_{2}^{3} \\
K_{3}^{3} \\
K_{4}^{3}\end{array}$ & $\begin{array}{l}4000000 \\
4000000 \\
4000000 \\
4000000\end{array}$ & $\begin{array}{l}100500 \\
100500 \\
100500 \\
100500\end{array}$ & 25125 \\
\hline $\mathrm{K}^{4}$ & 1200 & $\mathrm{~K}^{4}$ & 1200 & 1050 & 1050 \\
\hline $\mathrm{K}^{5}$ & 30 & $\begin{array}{l}K_{1}^{5} \\
K_{2}^{5}\end{array}$ & $\begin{array}{l}60 \\
60\end{array}$ & $\begin{array}{l}60 \\
60\end{array}$ & 30 \\
\hline
\end{tabular}

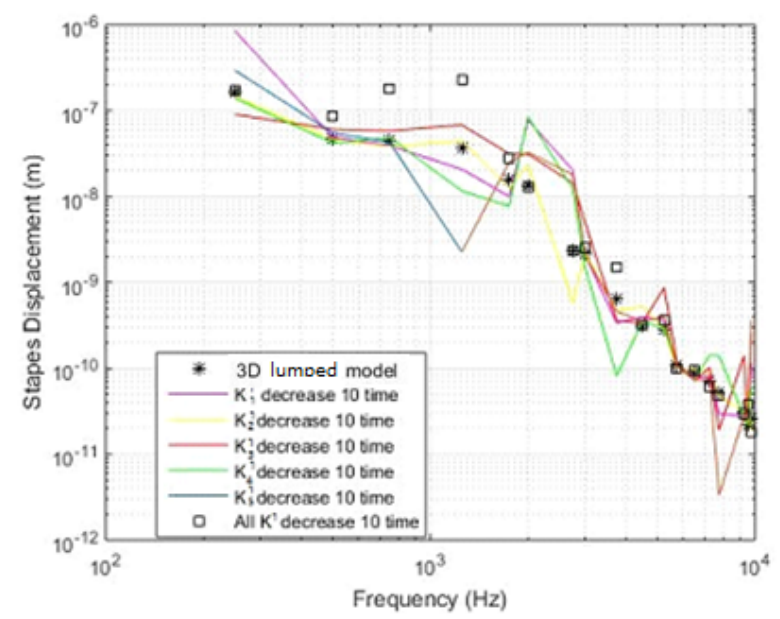

a) The stiffness of $K^{1}$ decreasing 10 times.

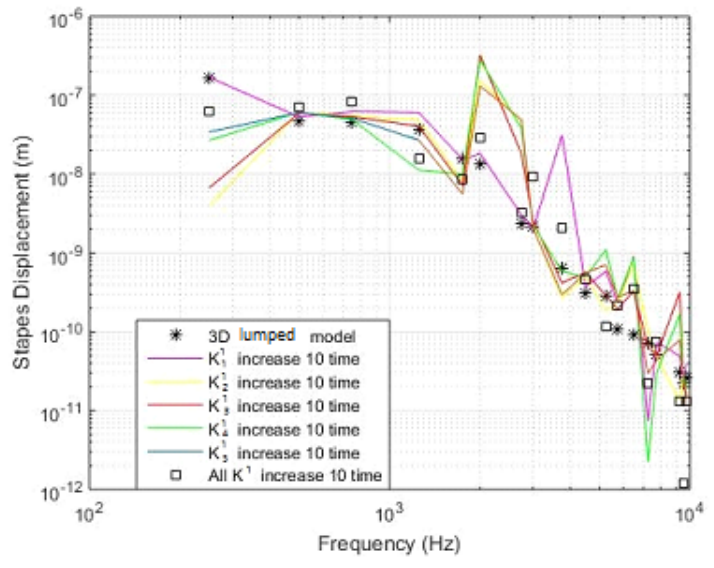

b) The stiffness of $\mathrm{K}^{1}$ increasing 10 times.

Figure 3. The $\mathrm{K}^{1}$ group of the stiffness changing from 0.1 to 10 times.

frequencies from 5000 to $7000 \mathrm{~Hz}$.

As shown in Fig. 7, it is obvious that stapes bone displacement had the largest influence on the I-S joint ( $\mathrm{K}^{4}$ spring). The green line indicates the higher trend when the spring increases and the lower one when the spring stiffness decreases 10 times. The M-I joint is the red line that is close to the original data in which the stiffness of the $\mathrm{K}^{3}$ changed by 10 times the stapes displacement.

\section{The effects of mass on the model}

The first result indicates the TM mass was increased by $4.17 \%$. The stapes displacement remained nearly unchanged, and only the mass of the TM pars tensa affected the stapes' vibration. In the figure, it is obvious that the magenta line and the black line are nearly parallel. The mass of the TM pars tensa affected the stapes' vibration. When the mass of the ear bone was increased by $8.33 \%$, the stapes' displacement decreased in the frequency ranges of 800 to $1800 \mathrm{~Hz}$ and 3000 to $5000 \mathrm{~Hz}$. At high frequencies $>5000 \mathrm{~Hz}$, the stapes' displacement increased. At frequencies ranging from 1800 to $3000 \mathrm{~Hz}$, the stapes' vibration remained steady. In the high-frequency ranges, the displacement increased a small amount. When the mass of each bone plus and minus $12.5 \%$ (which is almost the stapes' normal displacement) similar to the 3D lumped model, 


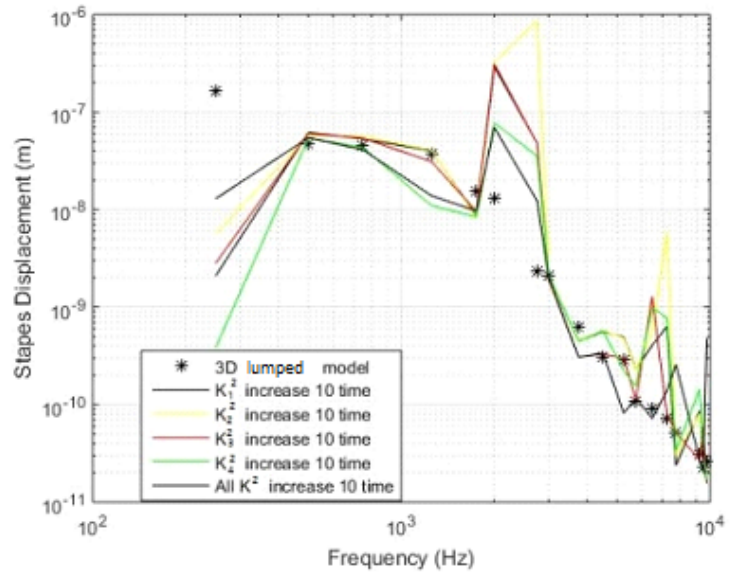

a) $\mathrm{K}^{2}$ increase 10 time.

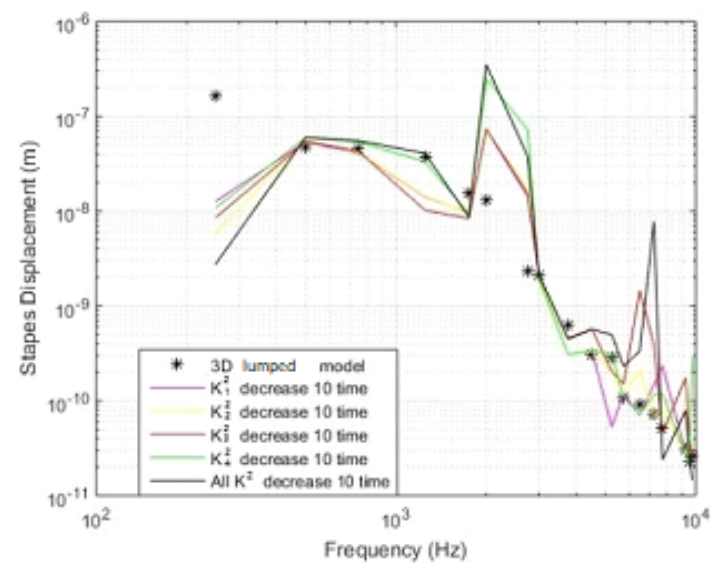

b) $\mathrm{K}^{2}$ decrease 10 time.

Figure 4. The effects of the $\mathrm{K}^{2}$ stiffness connection of TM-malleus and M-I joints on the model.

only the changes in the TM pars tensa mass produced a different result and had more effects on the ear bones' vibrations.

In Fig. 8, the stapes' displacement increases when the mass of the TM pars tensa decreases, and the stapes' displacement remains almost unchanged. Only the TM pars tensa had more effects on the stapes' displacement. When all of the mass of the ear bones were decreased by $200 \mathrm{~kg} / \mathrm{m}^{3}$, the stapes displacement (magenta line) was almost similar to the TM pars tensa line for all frequency from 250 to $10,000 \mathrm{~Hz}$. Only highfrequencies ranging from 6000 to $7500 \mathrm{~Hz}$ exerted an impact on the outcome.

Figure 9 shows that the TM pars tensa mass is a contributing factor that influences the stapes' vibration when the mass of the ear bone increase produces more vibrations than a mass decrease. When each of the ear bone's masses were increased by $41.7 \%$, the stapes' displacement became unstable at all frequencies. Specifically, at the frequencies from 250 to $700 \mathrm{~Hz}$, the value of the displacement increased. At frequencies from 700 to $2000 \mathrm{~Hz}$, the stapes displacement was lower than 3D lumped model, and other stapes' frequencies stapes did not measurably different results than the original ones.

By making substantial contributions to the outcome, the stapes' vibration was affected more by the TM pars tensa. As for other bone mass increases or decreases, the results were al-

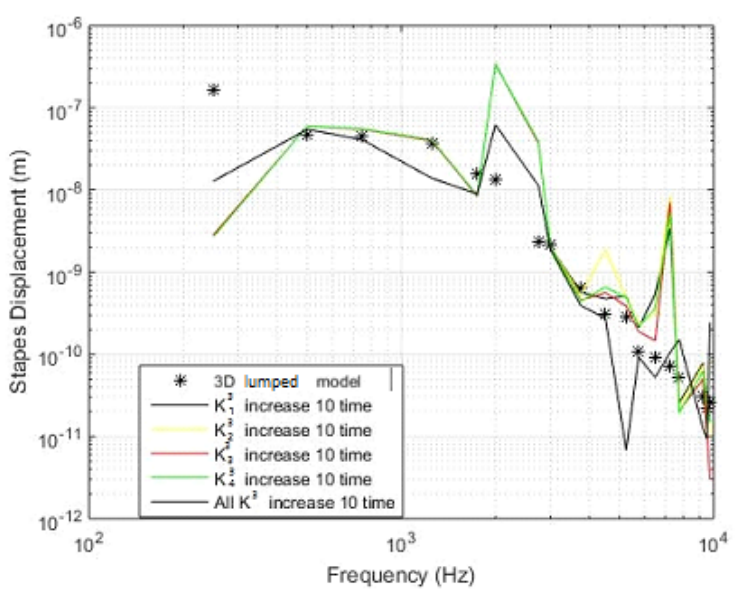

a) $\mathrm{K}^{3}$ increases 10 times.

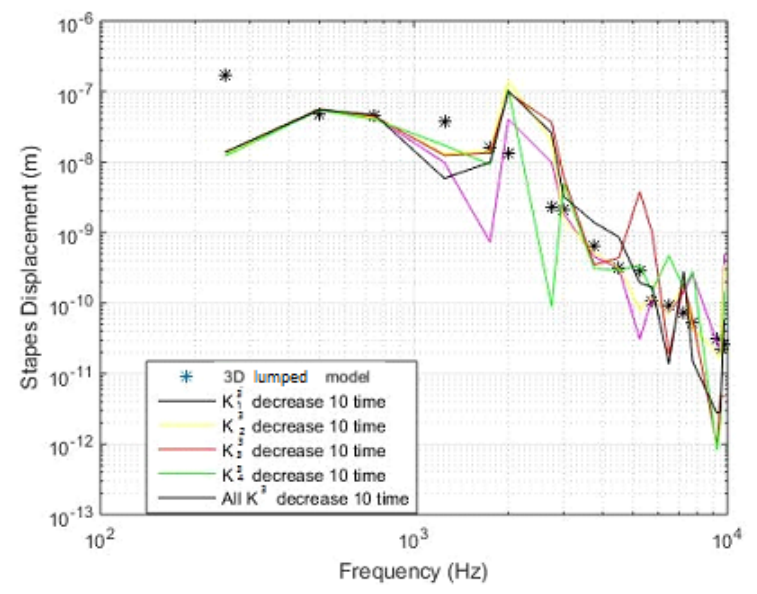

b) $\mathrm{K}^{3}$ decrease 10 time.

Figure 5. Effects of the $\mathrm{K}^{3} \mathrm{M}-\mathrm{I}$ on the model.

most as stable as the original model. The chart demonstrates that each person has a different ear bone mass and can hear different sounds with the different stapes-associated vibrations, but the most important vibration in the middle ear is associated with the mass of the TM pars tensa. It is one of the bones that plays a significant role in middle ear vibrations. ${ }^{29}$

The optimization process values were the same as the beginning parameter values at the start of optimization. The start values were determined by parameters from published models, ${ }^{1,3,23,25,30-35}$ and the limit of optimization was increased and decreased 10 times above and below the spring's original parameters. In order to check the steadiness of the results of this model, we used an improved method that resulted in a final stabilization answer for every spring's degree of stiffness.

\section{DISCUSSION}

In general, the different parts of the TM vibration had different amplitudes, and in the each of the joints that had some springs to be connected with two bones, the stiffness of the springs was changed; therefore, the results were changed. It can be seen in Fig. 3 that when each spring's stiffness at the first connection was changed 10 times, the second spring on this connection then had the least effect on TM and stapes displacement. The stapes displacement had a delta of only $4.42^{-7}$ 


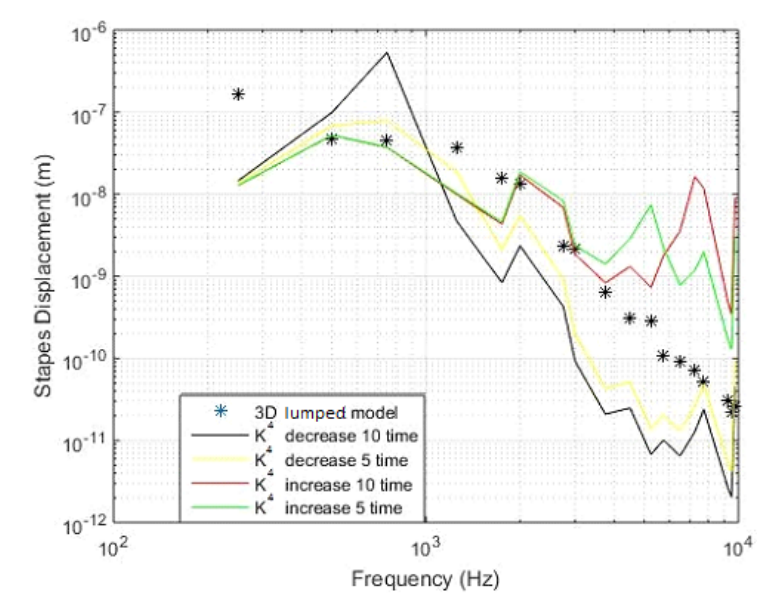

Figure 6. The effect of the $\mathrm{K}^{4}$ (stiffness of I-S joint) on this model.

$\mathrm{m}$ and variances calculated for this spring were $6.48^{-16}$ for all of the frequencies from 250 to $10,000 \mathrm{~Hz}$, which were comparatively small when compared with the other displacements. The TM-malleus connection had four connected springs and transferred the vibration from the TM to the Malleus as shown in Fig. 4. It is interesting to note that the first, second, and third connections of this spring had a smaller effect on the stapes' vibration compared to the others; they had a total delta displacement of the stapes for all frequencies from 250 to 10 , $000 \mathrm{~Hz}$, very near to $2.63^{-7}, 2.72^{-7}$, and $2.75^{-7}$, respectively. The last spring had a delta and variance of displacement much nearer to two times that of the others, and this spring had more effects on the stapes' vibration. In Fig. 5, for all frequencies from 250 to $10,000 \mathrm{~Hz}$, the spring's stiffness caused a decrease in the stapes' displacement to the same degree. In this case, the second spring was more effective, which caused a marked decrease in displacement. When the stiffness of the spring increased 10 times, the stapes' vibration had a variance similar to that of the joint. The second spring had the biggest displacement effect on the stapes.

The second discussion in this research concerns vibration,

Table 4. The variance of displacement for cases of increasing stiffness.

\begin{tabular}{|l|l|l|l|l|l||}
\hline Frequency & 2 times & 4 times & 6 times & 8 times & 10 times \\
\hline $\mathbf{2 5 0}$ & $2.32 \mathrm{E}-15$ & $9.73 \mathrm{E}-15$ & $1.55 \mathrm{E}-14$ & $1.96 \mathrm{E}-14$ & $2.26 \mathrm{E}-14$ \\
$\mathbf{5 0 0}$ & $1.99 \mathrm{E}-17$ & $3.85 \mathrm{E}-17$ & $4.55 \mathrm{E}-17$ & $4.90 \mathrm{E}-17$ & $5.12 \mathrm{E}-17$ \\
$\mathbf{7 5 0}$ & $8.37 \mathrm{E}-16$ & $1.57 \mathrm{E}-15$ & $1.83 \mathrm{E}-15$ & $1.97 \mathrm{E}-15$ & $2.06 \mathrm{E}-15$ \\
$\mathbf{1 0 0 0}$ & $1.09 \mathrm{E}-16$ & $1.22 \mathrm{E}-15$ & $2.99 \mathrm{E}-15$ & $4.96 \mathrm{E}-15$ & $6.92 \mathrm{E}-15$ \\
$\mathbf{1 2 5 0}$ & $2.15 \mathrm{E}-16$ & $2.09 \mathrm{E}-16$ & $1.29 \mathrm{E}-16$ & $6.77 \mathrm{E}-17$ & $2.94 \mathrm{E}-17$ \\
$\mathbf{1 7 5 0}$ & $6.14 \mathrm{E}-17$ & $9.02 \mathrm{E}-17$ & $9.80 \mathrm{E}-17$ & $1.02 \mathrm{E}-16$ & $1.04 \mathrm{E}-16$ \\
$\mathbf{2 7 5 0}$ & $1.39 \mathrm{E}-17$ & $2.77 \mathrm{E}-19$ & $1.53 \mathrm{E}-20$ & $1.26 \mathrm{E}-21$ & $1.45 \mathrm{E}-20$ \\
$\mathbf{3 0 0 0}$ & $1.68 \mathrm{E}-16$ & $1.69 \mathrm{E}-17$ & $2.02 \mathrm{E}-17$ & $2.66 \mathrm{E}-17$ & $3.41 \mathrm{E}-17$ \\
$\mathbf{3 5 0 0}$ & $1.10 \mathrm{E}-16$ & $2.03 \mathrm{E}-17$ & $9.88 \mathrm{E}-18$ & $8.37 \mathrm{E}-18$ & $8.16 \mathrm{E}-18$ \\
$\mathbf{3 7 5 0}$ & $1.48 \mathrm{E}-17$ & $1.28 \mathrm{E}-17$ & $2.20 \mathrm{E}-18$ & $9.49 \mathrm{E}-19$ & $5.54 \mathrm{E}-19$ \\
$\mathbf{4 7 5 0}$ & $6.05 \mathrm{E}-16$ & $4.60 \mathrm{E}-17$ & $4.76 \mathrm{E}-19$ & $3.75 \mathrm{E}-21$ & $1.00 \mathrm{E}-20$ \\
$\mathbf{5 5 0 0}$ & $7.78 \mathrm{E}-21$ & $5.61 \mathrm{E}-19$ & $1.58 \mathrm{E}-16$ & $1.50 \mathrm{E}-18$ & $5.00 \mathrm{E}-19$ \\
$\mathbf{6 7 5 0}$ & $3.10 \mathrm{E}-17$ & $2.91 \mathrm{E}-21$ & $6.65 \mathrm{E}-17$ & $6.33 \mathrm{E}-16$ & $3.13 \mathrm{E}-16$ \\
$\mathbf{7 5 0 0}$ & $2.64 \mathrm{E}-20$ & $1.75 \mathrm{E}-23$ & $1.48 \mathrm{E}-19$ & $2.80 \mathrm{E}-18$ & $1.39 \mathrm{E}-16$ \\
$\mathbf{7 7 5 0}$ & $2.10 \mathrm{E}-20$ & $1.02 \mathrm{E}-19$ & $1.49 \mathrm{E}-19$ & $4.03 \mathrm{E}-19$ & $2.57 \mathrm{E}-18$ \\
$\mathbf{8 0 0 0}$ & $6.52 \mathrm{E}-21$ & $3.45 \mathrm{E}-18$ & $6.43 \mathrm{E}-19$ & $9.69 \mathrm{E}-19$ & $3.44 \mathrm{E}-18$ \\
$\mathbf{8 7 5 0}$ & $6.18 \mathrm{E}-22$ & $5.79 \mathrm{E}-19$ & $2.07 \mathrm{E}-19$ & $1.93 \mathrm{E}-19$ & $3.71 \mathrm{E}-19$ \\
$\mathbf{9 2 5 0}$ & $6.47 \mathrm{E}-22$ & $3.27 \mathrm{E}-18$ & $5.91 \mathrm{E}-20$ & $8.06 \mathrm{E}-20$ & $1.44 \mathrm{E}-19$ \\
$\mathbf{1 0 0 0 0}$ & $3.45 \mathrm{E}-22$ & $2.34 \mathrm{E}-20$ & $2.37 \mathrm{E}-19$ & $5.45 \mathrm{E}-20$ & $6.62 \mathrm{E}-21$ \\
\hline Total & $4.51 \mathrm{E}-15$ & $1.3 \mathrm{E}-14$ & $2.08 \mathrm{E}-14$ & $2.74 \mathrm{E}-14$ & $3.22 \mathrm{E}-14$ \\
variance & & & & & \\
\hline Ratio & 2.8747011 & 1.606411 & 1.3156645 & 1.177207 & \\
\hline
\end{tabular}

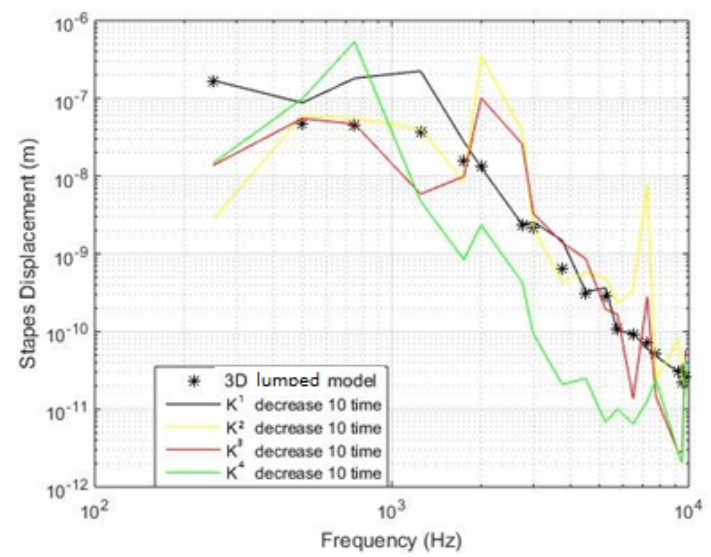

a) The effect of the stiffness decrease on $\mathrm{M}_{4}$ displacement.

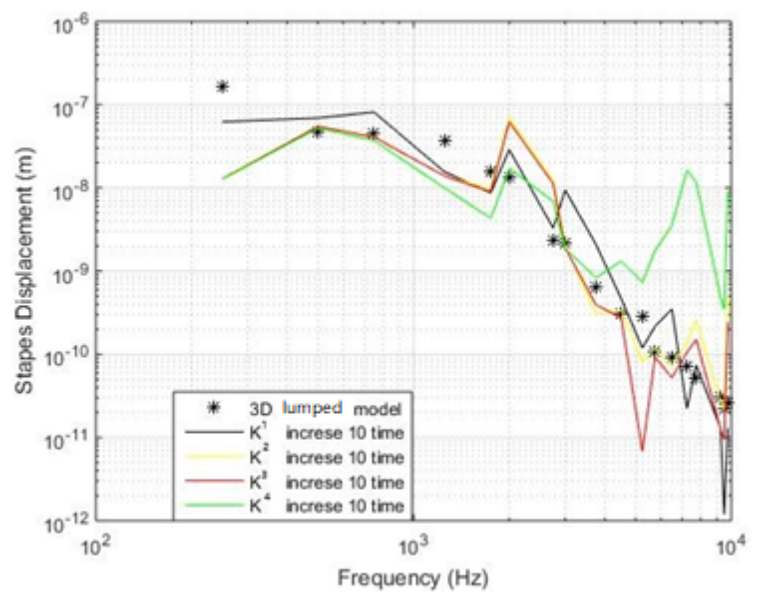

b) The effect of the stiffness increase on $\mathrm{M}_{4}$ displacement.

Figure 7. Effects of four stiffness systems on $\mathrm{M}_{4}$ displacement.

and the way in which to change it when we increase the stiffness by 2-10 times in increments of 2 . As shown in Fig. 10, the stapes' vibration changed gradually when the stiffness changed from 2 to 10 times in the frequencies ranging from 250 to 3000 $\mathrm{Hz}$. At a frequency of more than $3000 \mathrm{~Hz}$, the stapes' displacement changed more than at lower frequencies. It can be seen in Table 4 that the variance of the displacement in the frequency range from 250 to $3000 \mathrm{~Hz}$ did not change much, but after 3000 $\mathrm{Hz}$, the variance increased more than 10 times, and the maximum of the variance increased more than 50 times. In fact, when the stiffness increased from 2 to 10 times, the stapes' displacement had an increase in ratio. From 2 to 4 times, the variance's increase was 2.875 times; from 4 to 6 times, the variance increase dropped to 1.606 times, and from 8 to 10 times, the increase in variance was only 1.17 times.

As shown in the figure, we input the stiffness increase and decrease 10 times each using different ways to observe the results as seen in Fig. 11. As is presented in this model, in our connections, each of the joints had two ways to change the stiffness, and there was a total of 70 ways to complete the experiment. It is clear from the data that changing the stiffness of connections 2 and 4 would change the result quite noticeably in this model. The $\mathrm{K}^{2}$ and $\mathrm{K}^{4}$ springs had the greatest impact on the stapes' vibration.

From the total data among the five springs, it can easily be seen which spring caused the maximum change in the stapes' 


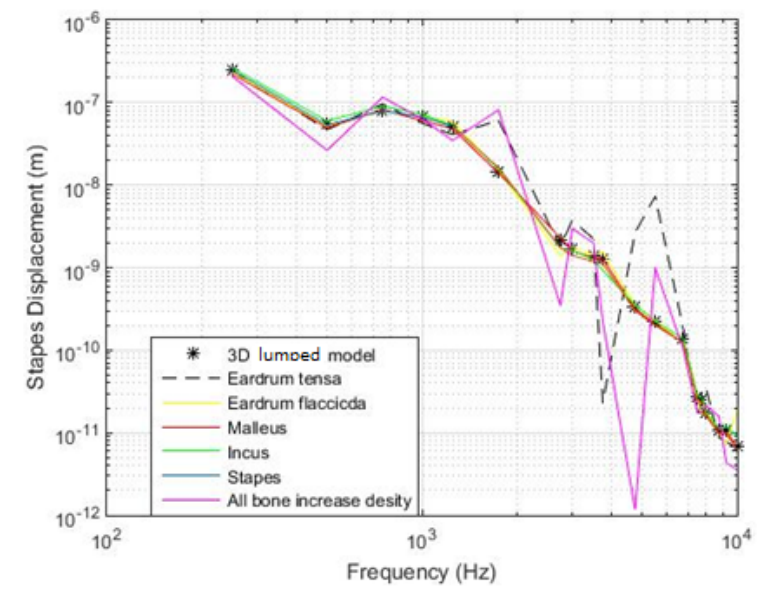

a) The mass of the ear bone with a $16.7 \%$ increase.

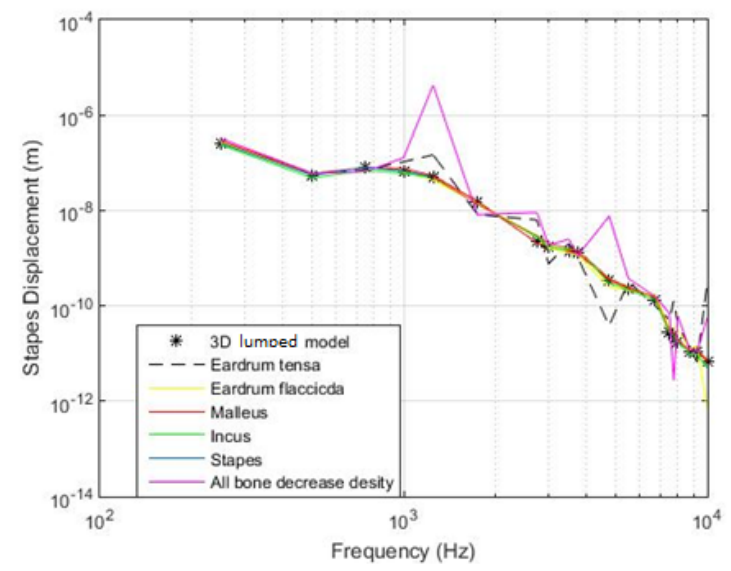

b) The mass of the ear bone with a $16.7 \%$ decrease.

Figure 8. The mass of the middle ear bone changed by $16.7 \%$.

displacement. In Table 5, the standard deviation of $\mathrm{K}^{2}{ }_{2}$ had the biggest number, and this spring had the greatest effect on the stapes' displacement.

In other discussions, we investigated the frequency that had

Table 5. Five springs having more effects on the value of the stapes' displacement.

\begin{tabular}{|l|l|l|l|l|l||}
\hline $\begin{array}{l}\text { Stiffness } \\
\text { of spring }\end{array}$ & $\mathbf{K}^{\mathbf{2}}{ }_{\mathbf{2}}$ & $\mathbf{K}^{\mathbf{2}}{ }_{\mathbf{3}}$ & $\mathbf{K}^{\mathbf{3}}{ }_{\mathbf{2}}$ & $\mathbf{K}^{\mathbf{2}}{ }_{\mathbf{4}}$ & $\mathbf{K}^{\mathbf{1}}{ }_{\mathbf{1}}$ \\
\hline & $5.58 \mathrm{E}-09$ & $2.80 \mathrm{E}-09$ & $1.31 \mathrm{E}-08$ & $3.81 \mathrm{E}-10$ & $1.69 \mathrm{E}-07$ \\
& $5.77 \mathrm{E}-08$ & $6.02 \mathrm{E}-08$ & $5.47 \mathrm{E}-08$ & $5.42 \mathrm{E}-08$ & $5.27 \mathrm{E}-08$ \\
& $5.61 \mathrm{E}-08$ & $5.40 \mathrm{E}-08$ & $4.22 \mathrm{E}-08$ & $4.33 \mathrm{E}-08$ & $6.20 \mathrm{E}-08$ \\
& $4.07 \mathrm{E}-08$ & $3.12 \mathrm{E}-08$ & $1.31 \mathrm{E}-08$ & $1.10 \mathrm{E}-08$ & $6.04 \mathrm{E}-08$ \\
& $8.31 \mathrm{E}-09$ & $9.57 \mathrm{E}-09$ & $1.43 \mathrm{E}-08$ & $8.42 \mathrm{E}-09$ & $1.52 \mathrm{E}-08$ \\
& $3.24 \mathrm{E}-07$ & $3.12 \mathrm{E}-07$ & $1.40 \mathrm{E}-07$ & $7.73 \mathrm{E}-08$ & $1.82 \mathrm{E}-08$ \\
Displace- & $8.60 \mathrm{E}-07$ & $4.81 \mathrm{E}-08$ & $1.98 \mathrm{E}-08$ & $3.54 \mathrm{E}-08$ & $3.01 \mathrm{E}-09$ \\
ment & $2.07 \mathrm{E}-09$ & $1.92 \mathrm{E}-09$ & $1.58 \mathrm{E}-09$ & $2.14 \mathrm{E}-09$ & $1.98 \mathrm{E}-09$ \\
result (m) & $4.56 \mathrm{E}-10$ & $3.09 \mathrm{E}-10$ & $5.19 \mathrm{E}-10$ & $4.45 \mathrm{E}-10$ & $3.10 \mathrm{E}-08$ \\
& $5.74 \mathrm{E}-10$ & $3.31 \mathrm{E}-10$ & $3.14 \mathrm{E}-10$ & $5.70 \mathrm{E}-10$ & $3.68 \mathrm{E}-10$ \\
& $4.83 \mathrm{E}-10$ & $3.00 \mathrm{E}-10$ & $8.20 \mathrm{E}-11$ & $2.24 \mathrm{E}-10$ & $5.87 \mathrm{E}-10$ \\
& $2.24 \mathrm{E}-10$ & $1.12 \mathrm{E}-10$ & $1.19 \mathrm{E}-10$ & $1.54 \mathrm{E}-10$ & $2.28 \mathrm{E}-10$ \\
& $5.54 \mathrm{E}-10$ & $1.28 \mathrm{E}-09$ & $7.19 \mathrm{E}-11$ & $9.87 \mathrm{E}-10$ & $9.15 \mathrm{E}-10$ \\
& $5.86 \mathrm{E}-09$ & $7.95 \mathrm{E}-11$ & $1.90 \mathrm{E}-10$ & $7.68 \mathrm{E}-10$ & $7.31 \mathrm{E}-12$ \\
& $2.98 \mathrm{E}-11$ & $5.19 \mathrm{E}-11$ & $4.28 \mathrm{E}-11$ & $3.39 \mathrm{E}-11$ & $7.43 \mathrm{E}-11$ \\
& $8.12 \mathrm{E}-11$ & $2.71 \mathrm{E}-11$ & $1.98 \mathrm{E}-11$ & $1.43 \mathrm{E}-10$ & $4.91 \mathrm{E}-11$ \\
\hline $\begin{array}{l}\text { Standard } \\
\text { deviation }\end{array}$ & $3.56 \mathrm{E}-11$ & $5.85 \mathrm{E}-11$ & $1.71 \mathrm{E}-11$ & $3.36 \mathrm{E}-11$ & $2.52 \mathrm{E}-11$ \\
\hline & $1.95 \mathrm{E}-11$ & $1.55 \mathrm{E}-11$ & $3.50 \mathrm{E}-10$ & $1.68 \mathrm{E}-11$ & $3.91 \mathrm{E}-11$ \\
\hline
\end{tabular}

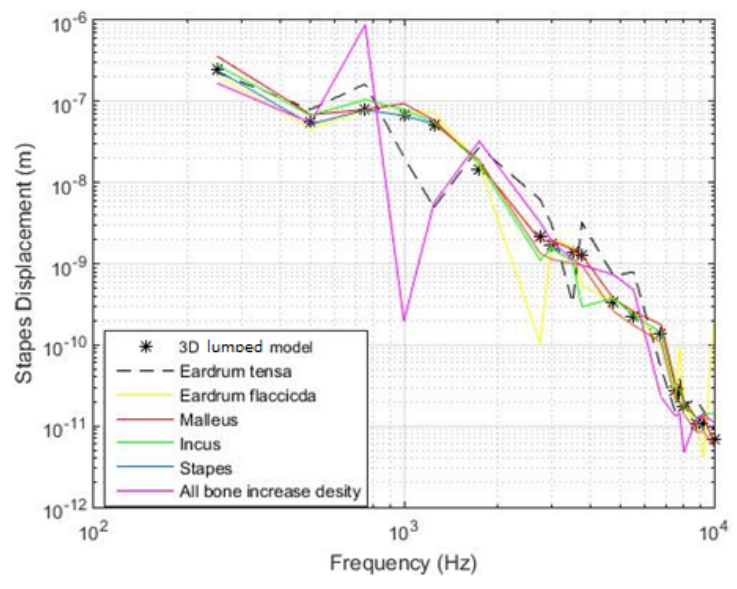

a) The mass of ear bone increases by $41.7 . \%$

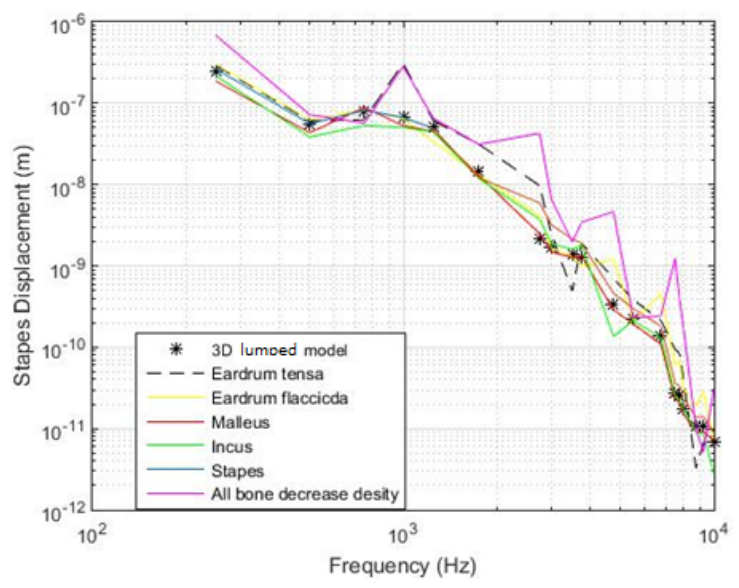

b) The mass of ear bone decreases by $41.7 . \%$

Figure 9. Mass of middle ear bone increase and decrease by $41.7 \%$.

the biggest vibration when we stimulated the development of the stiffness of the spring. The data revealed that each of the frequencies had one maximum and one minimum displacement result. Then, in Table 6 , we can see that there were five frequencies of $250,750,1250,2000$, and $2750 \mathrm{~Hz}$, all of which caused the biggest difference in stapes' displacement and five frequencies of 250, 750, 1250, 1750, and $2000 \mathrm{~Hz}$, all of which caused the lowest difference in displacement value. Four out of the five frequencies caused the largest and smallest difference in displacement; these were considered the four sensitive frequencies.

In Fig. 12, the stiffness increased from 2 to 10 times, and the ratio of the standard deviation increased from 0.128 to 0.342 $\mathrm{Ns} / \mathrm{m}$. In the case of a 10-time increase, the result was quite different from the original value, and it is apparent that the effect on the spring vibration was inside the ear bone. This figure is representative of patients with atherosclerosis in which the ligaments and joints are calcified and hardened, thus greatly reducing their ability to hear. This phenomenon occurs as long as the hearing ability of the patient decreases. Our 3D lumped model can be used to predict a sharp decrease in the stapes' response, which would result in serious hearing loss sound transmission in the middle ear.

Other way, each person will have structural, shape, and 


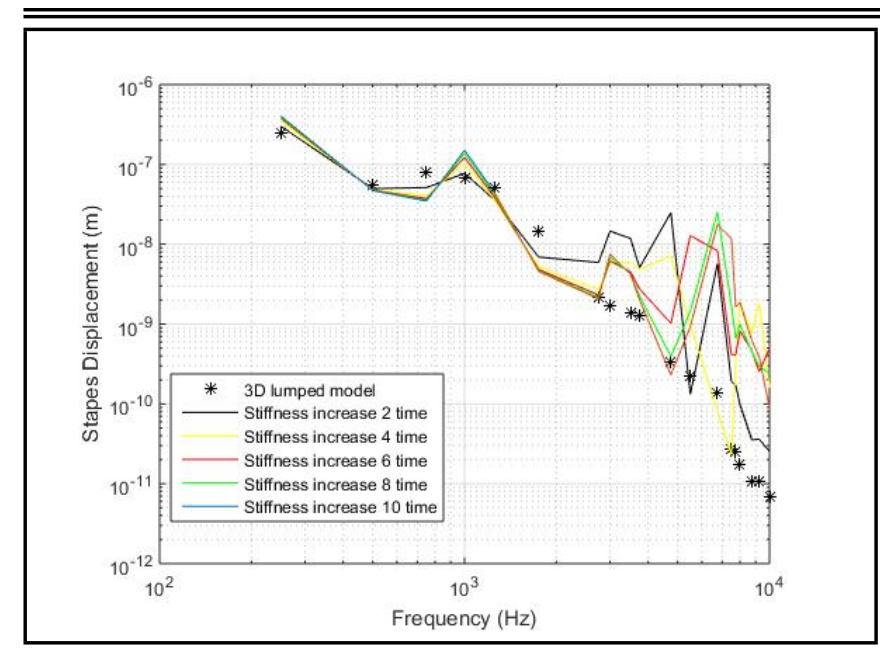

Figure 10. Comparison of the stapes' displacement when the stiffness of the spring increase 2-10 times in increments of 2 .

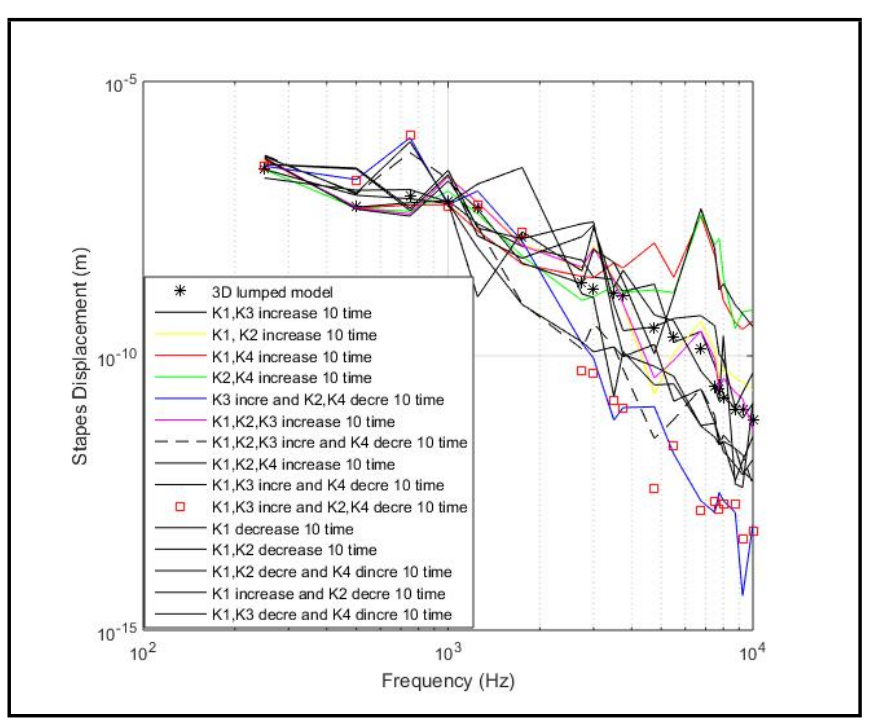

Figure 11. The stapes displacement for all joints changed spring stiffness in different ways.

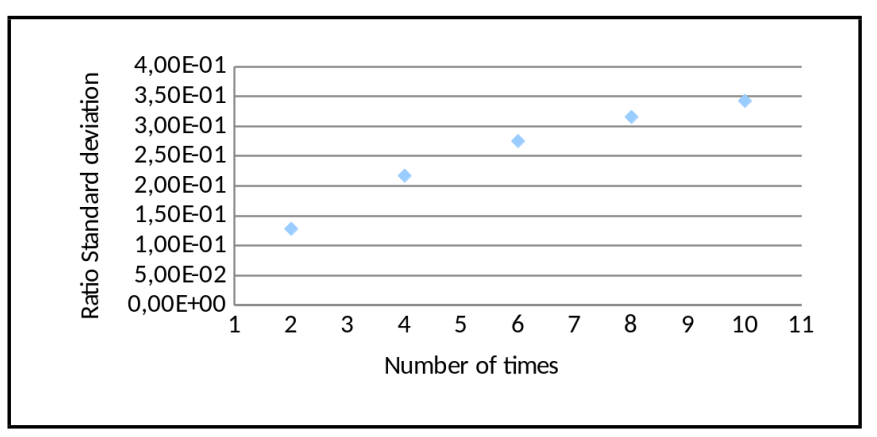

Figure 12. The ratios of the standard deviation over time.

weight ear bone differences that causes the resulting vibrations on the stapes inside ear bone to be different. From these results, the important effect on the vibration of stapes is the TM pars tensa mass. When the mass of ear bone either increases or decreases by $4.17 \%$, the variation in the stapes' displacement associated with the TM pars tensa was about two time larger than the stapes' displacement that was associated with other ear bone mass increases and decreases. When the mass of the ear bone changed from $8.33 \%$ to $41.7 \%$, the stapes' vibration
Table 6. The maximum and minimum displacement of each of the frequencies.

\begin{tabular}{||l|l|l|l|l||}
\hline Frequency & $\begin{array}{l}\text { The maximum } \\
\text { of } \\
\text { ment }\end{array}$ & $\begin{array}{l}\text { Delta of max } \\
\text { displace }\end{array}$ & $\begin{array}{l}\text { The min. of } \\
\text { the displace- } \\
\text { ment }\end{array}$ & $\begin{array}{l}\text { Delta of min } \\
\text { displace- } \\
\text { ment }\end{array}$ \\
\hline $\mathbf{2 5 0}$ & $8.46 \mathrm{E}-07$ & $6.7999 \mathrm{E}-07$ & $3.81 \mathrm{E}-10$ & $-1.6524 \mathrm{E}-07$ \\
$\mathbf{5 0 0}$ & $9.90 \mathrm{E}-08$ & $5.1327 \mathrm{E}-08$ & $4.18 \mathrm{E}-08$ & $-5.832 \mathrm{E}-09$ \\
$\mathbf{7 5 0}$ & $5.32 \mathrm{E}-07$ & $4.86705 \mathrm{E}-07$ & $3.71 \mathrm{E}-08$ & $-7.715 \mathrm{E}-09$ \\
$\mathbf{1 2 5 0}$ & $2.24 \mathrm{E}-07$ & $1.87726 \mathrm{E}-07$ & $2.26 \mathrm{E}-09$ & $-3.4454 \mathrm{E}-08$ \\
$\mathbf{1 7 5 0}$ & $3.14 \mathrm{E}-08$ & $1.569 \mathrm{E}-08$ & $7.31 \mathrm{E}-10$ & $-1.4982 \mathrm{E}-08$ \\
$\mathbf{2 0 0 0}$ & $3.51 \mathrm{E}-07$ & $3.38003 \mathrm{E}-07$ & $2.35 \mathrm{E}-09$ & $-1.088 \mathrm{E}-08$ \\
$\mathbf{2 7 5 0}$ & $8.60 \mathrm{E}-07$ & $8.57574 \mathrm{E}-07$ & $8.88 \mathrm{E}-11$ & $-2.2176 \mathrm{E}-09$ \\
$\mathbf{3 0 0 0}$ & $9.40 \mathrm{E}-09$ & $7.28 \mathrm{E}-09$ & $9.26 \mathrm{E}-11$ & $-2.0252 \mathrm{E}-09$ \\
$\mathbf{3 7 5 0}$ & $3.10 \mathrm{E}-08$ & $3.03763 \mathrm{E}-08$ & $2.09 \mathrm{E}-11$ & $-6.0879 \mathrm{E}-10$ \\
$\mathbf{4 5 0 0}$ & $2.88 \mathrm{E}-09$ & $2.56629 \mathrm{E}-09$ & $2.49 \mathrm{E}-11$ & $-2.8817 \mathrm{E}-10$ \\
$\mathbf{5 2 5 0}$ & $7.38 \mathrm{E}-09$ & $7.09541 \mathrm{E}-09$ & $6.77 \mathrm{E}-12$ & $-2.8262 \mathrm{E}-10$ \\
$\mathbf{5 7 5 0}$ & $2.25 \mathrm{E}-09$ & $2.14322 \mathrm{E}-09$ & $1.01 \mathrm{E}-11$ & $-9.8409 \mathrm{E}-11$ \\
$\mathbf{6 5 0 0}$ & $3.53 \mathrm{E}-09$ & $3.43501 \mathrm{E}-09$ & $6.46 \mathrm{E}-12$ & $-8.5532 \mathrm{E}-11$ \\
$\mathbf{7 2 5 0}$ & $1.63 \mathrm{E}-08$ & $1.62628 \mathrm{E}-08$ & $2.23 \mathrm{E}-12$ & $-7 \mathrm{E}-11$ \\
$\mathbf{7 7 5 0}$ & $1.18 \mathrm{E}-08$ & $1.17615 \mathrm{E}-08$ & $3.33 \mathrm{E}-12$ & $-4.8187 \mathrm{E}-11$ \\
$\mathbf{9 2 5 0}$ & $4.87 \mathrm{E}-10$ & $4.56009 \mathrm{E}-10$ & $8.30 \mathrm{E}-13$ & $-2.9741 \mathrm{E}-11$ \\
$\mathbf{9 5 0 0}$ & $3.46 \mathrm{E}-10$ & $3.2343 \mathrm{E}-10$ & $1.19 \mathrm{E}-12$ & $-2.144 \mathrm{E}-11$ \\
$\mathbf{9 7 5 0}$ & $8.99 \mathrm{E}-09$ & $8.95967 \mathrm{E}-09$ & $2.97 \mathrm{E}-12$ & $-2.2858 \mathrm{E}-11$ \\
\hline
\end{tabular}

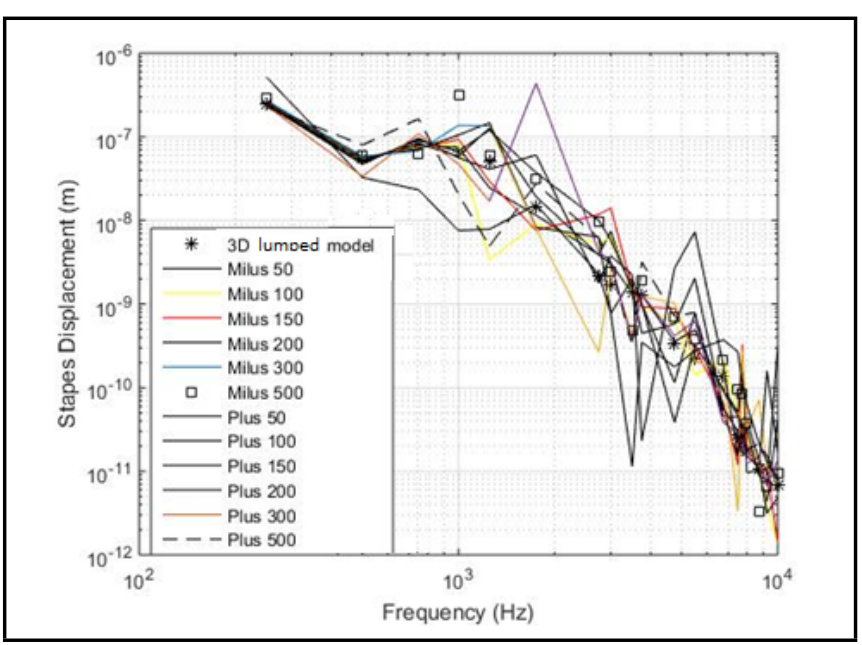

Figure 13. Comparison of the stapes' displacement when the mass of the TM pars tensa changes.

was always biggest when the mass of TM pars tensa changed. In Figure 13, the stapes' displacement associated with the TM pars tensa mass changed from $-41.7 \%$ to $41.7 \%$.

In Fig. 14, it can be seen that the stapes' displacement presents a moderate increase of 1.2 and 1.4 times. After that point, the stapes' vibration will decrease when the masses of the bones in middle ear increases, and the stapes' displacement will be more significantly reduced in the high-frequency range. The figure shows that when the mass increases more, the stapes' displacement decreases more at high frequencies. The mass of the ear bones produces a noticeable increase in the stapes' vibration. This suggests that when the three calcified ossicles (stapes, incus, and malleus) become calcified or age, changes in bone weight will reduce their capabilities to transmit sound to the cochlea. Using this model, doctors can predict and provide the best treatment for the patient.

The temporal bone, as shown in the 3D lumped model, showed an initial mode frequency of $f_{0}=1.15 \pm 0.23 \mathrm{kHz}$ when the model changed the spring stiffness and density of the ear bone's material that is reflected as air conduction have range of frequency around $800-1200 \mathrm{~Hz} .{ }^{35}$ For the second mode of middle ear model with a frequency of $f_{l}=1.74 \pm 0.21 \mathrm{kHz}$, the 


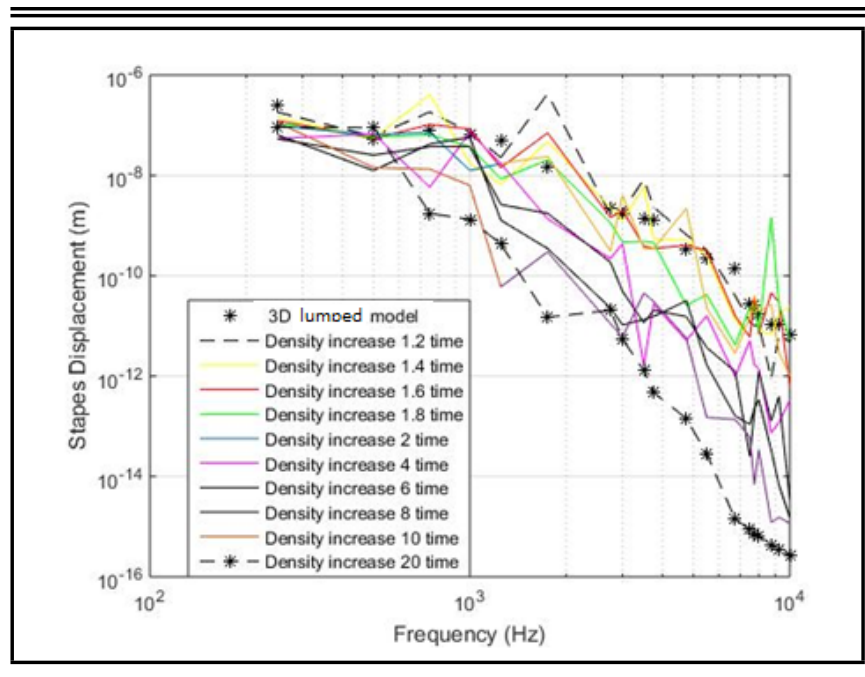

Figure 14. Comparison of the stapes' displacement after the ear bones' mass increased.

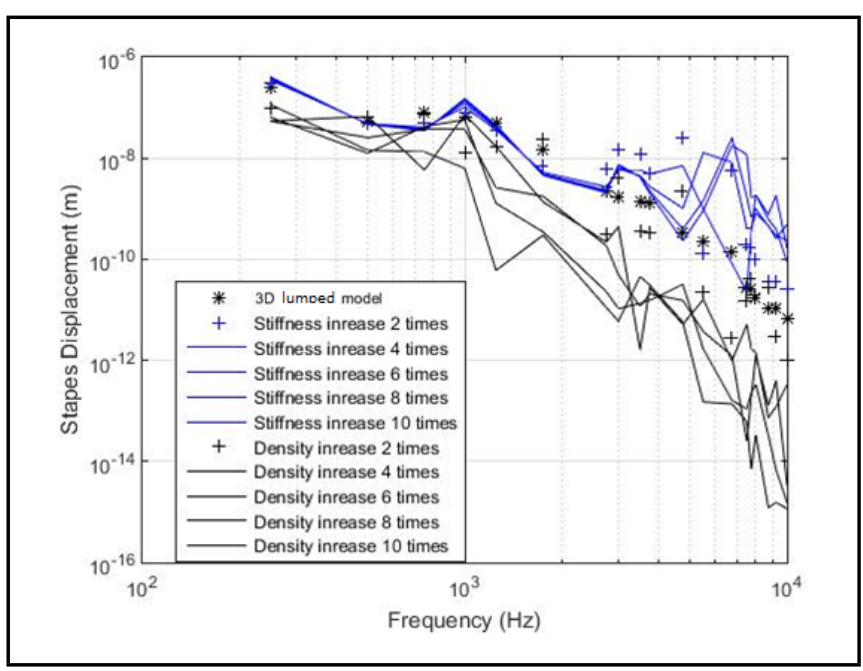

Figure 15. Comparison of the stapes displacement when the ear bone mass and the spring stiffness of change.

model consists mostly of the bone conduction in range of frequency range of 1500 to $2000 \mathrm{~Hz}$ as presented by Kenji. ${ }^{35}$ The third mode had a frequency of $1.99 \pm 0.25 \mathrm{kHz}$, which was still in line with a bone conduction hearing mechanism in the midfrequency range around $2 \mathrm{kHz}$. The finding is consistent with the hypothesis for the resonance of a middle-ear model in bone conduction limit data.

The stapes' displacement with respect to ear bone mass presented an upward trend from 2 to 10 times with the stiffness of the connection increasing from 2 to 10 times. In Fig. 15, the stapes' displacement when we change the mass of the ear bone is presented as the blue line, and the black line is the stapes' displacement when changing the spring's stiffness. The result shows that the stapes' displacement associated with the changing ear bone stiffness was slightly higher than the original results and the stapes' displacements associated with the ear bone mass was insignificant. From these results, it can be seen that the important effect on middle ear bone vibration is the ear bone joint stiffness. The 3D lumped model on this paper is simple but can be used for in silico middle ear ligament and tendon simulations.

The ratios of the umbo and stapes displacements are shown

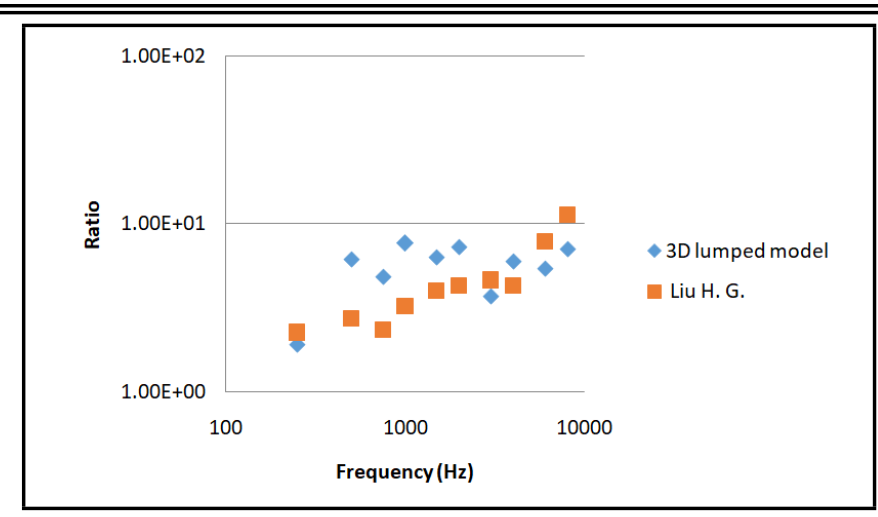

Figure 16. The ratio of the umbo and stapes displacements.

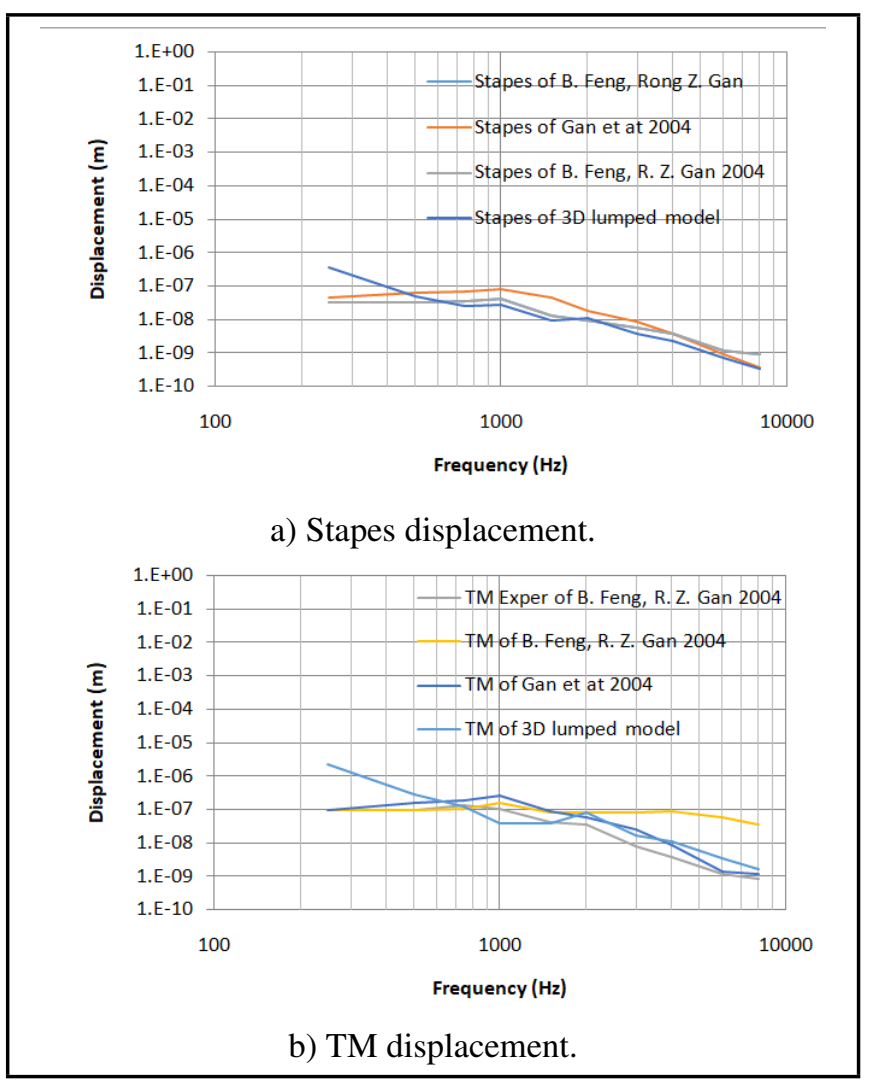

Figure 17. Comparison of the 3D lumped model results.

in Fig. 16. For the low and high frequency portions, the ratio results of the 3D lumped model are nearly the same as that of Liu et al. ${ }^{23}$ For the middle frequency (from 1 to $3 \mathrm{kHz}$ ), the ratio of the umbo displacement of 3D lumped model is slightly higher than that of Liu et al. In other words, the 3D lumped model yields a better description of the noise transmission phenomena from the TM to the stapes than the Liu et al model.

The displacement of TM and stapes presented by the 3D lumped model in Fig. 17 shows the way in which the TM and stapes displacement of the 3D lumped model at low frequencies were slightly different, whereas at the high frequencies ranging from 1 to $5 \mathrm{kHz}$, the 3D lumped results are nearly equivalent with the experimental results from Gan et al. ${ }^{1}$ On the lumped model by Feng and Gan, the high frequencies yield TM displacement with more pronounced differences than seen with the 3D lumped model. The results show that TM displacement of 3D lumped model have clearer results than seen 
in the lumped model from Gan et al. For the stapes displacement at the high frequencies, the results from the lumped and 3D lumped models are nearly the same. At the low frequencies from 250 to $750 \mathrm{~Hz}$, the results from the 3D lumped are slightly higher than the lumped model's results, but at frequencies more than $750 \mathrm{~Hz}$, the results from the 3D lumped model are close to the results from the lumped model from Gan et al. It is evident that the 3D lumped model is simpler than the model by Feng et al. with only four masses but nearly the same experiment results. This shows that the proposed 3D lumped model can be used for predicting the effect of the connective stiffness on middle ear sound transmission.

\section{CONCLUSION}

The 3D lumped model of the middle ear is based on previously published data and our parameterizations. The detailed discussion concerning the sensitivity of those parameters is provided with the appropriate applications for the sound transmission in the ear, including the change in the system stiffness of the TM system $\left(\mathrm{K}^{1}\right)$, the TM-malleus connective system $\left(\mathrm{K}^{2}\right)$, the $\mathrm{M}-\mathrm{I}$ joint system $\left(\mathrm{K}^{3}\right)$, the I-S joint system $\left(\mathrm{K}^{4}\right)$, and the connection between the stapes and cochlea $\left(\mathrm{K}^{5}\right)$. The 16 springs in the model were determined by comparing the model predictions at the $\mathrm{M}_{4}$ level using the experimental stapes displacement data of the human ear bone system. Of the five major springs' systems, there was a total of 16 springs connected to the bones $\mathrm{M}_{1}-\mathrm{M}_{4}$. The $\mathrm{M}_{3}$ connection affects the stapes displacement the least. The magnitude order of the sensitivity of the four connection system's stiffness to the stapes displacement was $K^{4}>K^{2}>K^{1}>K^{3}>K^{5}$. If any one of the five system stiffnesses was larger than that of the original case's corresponding system stiffness, the order of the magnitude of affecting the stapes displacement would be $\mathrm{K}^{2}>\mathrm{K}^{3}>\mathrm{K}^{4}>\mathrm{K}^{1}>\mathrm{K}^{5}$. Even at twice that of the system stiffness of the ear mechanical model, the difference of the stapes displacement showed around $14 \%$ of the original value. The validation of our 3D lumped model verified that our model can be used to simulate the human ear close to real-life situations. It is worth noting that changing the descriptive results of the details from the 3D lumped model will guide model editing in order to achieve the best simulation feature for the human ear. This result helped us make a component that supports or replaces the links of the ear bone in the human ear. The main purpose of this article was to construct a simple model to be used for computer simulation of middle ear ligaments and tendons that can be used to diagnose pathologies that lead to a hearing decrease or loss.

On the other hand, the change in the magnitude of the mass of the ear bone system caused by a 90-decibel sound transmission through the middle of the ear is useful for understanding the effect of mass on the vibration of the stapes. The most important vibrational effects were on ear bones' masses via the TM pars tensa. The magnitude of the mass of the TM pars tensa was the second major factor that affected the stapes' displacement. Under the magnitude of the four masses of the mass system, which was smaller than the normal level, the stapes/ displacement was almost similar to that of the TM pars tensa at frequencies ranging from 250 to $10,000 \mathrm{~Hz}$. However, the bigger magnitude of the whole mass yielded a smaller stapes' vibrational amplitude. Besides the mass system, the connection system was also an important component of the middle ear's computational model. Because of both of the stiffness of the connection system and the ear bone masses, the stapes displacement vibration was affected by variations in stiffness more than variations in mass. Using this model, doctors can predict and provide the best treatment for patients, which would in turn help patients recover some of their hearing.

\section{REFERENCES}

1 Feng, B., Gan, R. Z., Lumped parametric model of the human ear for sound transmission, Biomechanics and Modeling in Mechanobiology, 3, 33-47, (2004). https://dx.doi.org/10.1007/s10237-004-0044-9

2 Zwislocki, J. J., Analysis of the middle ear function. Part I: input impedance. Journal of the Acoustical Society of America, 34, 1514-1523, (1962). https://dx.doi.org/10.1121/1.1918382

3 Kringlebotn, M., Network model for the human middle ear, Scandinavian Audiology, 17, 75-85, (1988). https://dx.doi.org/10.3109/01050398809070695

${ }^{4}$ Gan, R. Z. , Sun, Q., Dyer, R. K., Chang, K. H., Dormer, K. J., Three-dimensional modeling of middle ear biomechanics and its applications, Otology \& Neurotology, 23, 271-280, (2002). https://dx.doi.org/10.1097/00129492200205000-00008

5 Meister, H., Walger, M., Mickenhagen, A., von Wedel, H., Stennert, E., Standardized measurements of the sound transmission of middle ear implants using a mechanical middle ear model, European Archives of Otorhinolaryngology, 256, 122-127, (1999). https://dx.doi.org/10.1007/s004050050123

6 Møller, A. R., Network model of the middle ear, Journal of the Acoustical Society of America, 33, 168-176, (1961). https://dx.doi.org/10.1121/1.1908610

7 Hudde, H., Weistenhofer, C., Circuit model of middle ear function, In: Rosowski JJ, Merchant SN (eds) The function and mechanics of normal, diseased and reconstructed middle ears, Kugler Publications, The Hague, The Netherlands. 2000. https://dx.doi.org/10.1007/s004050050123

8 Kelly, D. J., Prendergast, P. J., Blayney, A. W., The effect of pros-thesis design on vibration of the reconstructed ossicular chain: a comparative finite element analysis of four prostheses, Otology \& Neurotology, 24, 11-19, (2003). https://dx.doi.org/10.1097/00129492-200301000-00004

9 Taschke, H., Weistenhofer, C., Hudde, H., A full-sized physical model of the human middle ear, Acta Acustica united with Acustica, 86, 103-116, (2000).

10 Håkansson, B., Carlsson, P., Skull simulator for direct bone conduction hearing devices, 
Scandinavian Audiology, 18, 91-98, (2000). https://dx.doi.org/10.3109/01050398909070728

11 Sun, Q., Gan, R. Z., Chang, K. H., Dormer, K. J., Computer-integrated finite element modeling of human middle ear, Biomechanics and Modeling in Mechanobiology, 1, 109-122, (2002). https://dx.doi.org/10.1007/s10237-002-0014-z

12 Volandri, G., Di Puccio, F., Forte, P., Carmignani, C., Biomechanics of the tympanic membrane, Journal of Biomechanics, 44, 1219-1236, (2011). https://dx.doi.org/10.1016/j.jbiomech.2010.12.023

13 Wever, E. G., Lawrence, M., Physiological acoustic. Princeton University Press, Princeton, New Jersey, (1954). https://dx.doi.org/10.1515/9781400876433

14 Von Békésy, G., Experiments in hearing. McGraw-Hill, New York, (1960).

15 Kirikae, I., The structure and function of the middle ear. Tokyo University Press, Tokyo, (1960).

16 Gan, R. Z., Wood, M. W., Dormer, K. J., Human middle ear transfer function measured by double laser interferometry system, Otology \& Neurotology, 25 (4), 423-435, (2004). https://dx.doi.org/10.1097/00129492-200407000-00005

17 Goode, R. L., Killian, M., Nakamura, K., Nishihara, S., New knowledge about the function of the human middle ear: development of an improved analog model, American Journal of Otolaryngology, 15, 145-154, (1994). https://dx.doi.org/10.1016/0196-0709(94)90068-X

18 Gan, R. Z., Dyer, R. K., Wood, M. W., Dormer, K. J., Mass loading on ossicles and middle ear function, Annals of Otology, Rhinology and Laryngology, 110, 478-485, (2001). https://dx.doi.org/10.1177/000348940111000515

19 Gentil, F., Parente, M., Martins, P., Garbe, C., Jorge, R. N., Ferreira, A., Tavares, J. M. R. S., The influence of the mechanical behavior of the middle ear ligaments: a finite element analysis, Proc. IMechE Vol. 225 Part H: J. Engineering in Medicine, 225, 68-76, (2011). https://dx.doi.org/10.1243/09544119JEIM783

20 Zhao, F., Koike, T., Wang, J., Sienz, H., Meredith, R., Finite element analysis of the middle ear transfer functions and related pathologies, Medical Engineering \& Physics, 31, 907-916, (2009). https://dx.doi.org/10.1016/j.medengphy.2009.06.009

21 Gan, R. Z., Sun, Q., Feng, B., Wood, M. W., Acoustic-structural coupled finite element analysis for sound transmission in human ear-Pressure distributions, Medical Engineering \& Physics, 28, 395-404, (2006). https://dx.doi.org/10.1016/j.medengphy.2005.07.018

22 Kringlebotn, M., Gundersen, T., Frequency characteristics of the middle ear, Journal of the Acoustical Society of America, 77, 159-164, (1985). https://dx.doi.org/10.1121/1.392280
23 Liu, H. G., Rao, Z., Ta, N., Finite element analysis of the effects of a floating mass transducer on the performance of a middle ear implant, Journal of Medical Engineering \& Technology, 34 (5-6), 316-323, (2010). https://dx.doi.org/10.3109/03091902.2010.481033

24 Lutman, M. E., Martin, A. M., Development of an electroacoustic analogue model of the middle ear and acoustic reflex, Journal of Sound and Vibration, 64, 133-157, (1979). https://dx.doi.org/10.1016/0022-460X(79)90578-9

25 Funnell, W. R. J., Decraemer, W. F., Khanna, S. M., On the damped frequency response of a finiteelement model of the cat eardrum, Journal of the Acoustical Society of America, 81, 1851-1859, (1987). https://dx.doi.org/10.1121/1.394749

26 Koike, T., Wada, H., Modeling of the human middle ear using the finite-element method, Journal of the Acoustical Society of America, 111 (3), 1306-1317, (2002). https://dx.doi.org/10.1121/1.1451073

27 Wada, H., Metoki, T. Analysis of dynamic behavior of human middle ear using a finite method. Journal of the Acoustical Society of America, 92 (6), 3157-1368, (1992). https://dx.doi.org/10.1121/1.404211

28 Funnell, W. R. J., Laszlo, C. A., Modeling of the cat eardrum as a thin shell using the finite-element method, Journal of the Acoustical Society of America 63, 14611467, (1978). https://dx.doi.org/10.1121/1.381892

29 Rabbitt, R. D., Holmes, M. H., A fibrous dynamic continuum model of the tympanic membrane, Journal of the Acoustical Society of America, 80 (6), 1716-1728, (1986). https://dx.doi.org/10.1121/1.394284

30 Bornitz, M., Zahnert, T., Hardtke, H. J., Huttenbrink, K. B., Identification of parameters for the middle ear, Audiology and Neurotology, 4, 163-169, (1999). https://dx.doi.org/10.1159/000013836

31 Nishihara, S., Goode, R. L., Measurement of tympanic membrane vibration in 99 human ear. In K.B. Huttenbrink (Ed.) Middle Ear Mechanics in Research and Otosurgery, 19-22, (1996), Dresden University of Technology.

32 Fletcher, R., Practical methods of optimization. vol. 1, Unconstrained optimization and vol. 2, Constrained optimization, Wiley, New York, (1980).

33 Davis, H., Anatomy and physiology of the auditory system. In: Davis H, Silverman SR (eds) Hearing and deafness, 3rd edn. Holt, Rinehart \& Winston, New York, (1978).

34 Stinson, M. R., Specification of the geometry of the human ear canal for the prediction of sound-pressure level distribution, Journal of the Acoustical Society of America, 85, 2492-2503, (1989). https://dx.doi.org/10.1121/1.397744 
35 Kenji, H., Yu, D., Ossicular resonance modes of the human middle ear for bone and air conduction, Journal of the Acoustical Society of America, 125 (2), 968-979, (2008). https://dx.doi.org/10.1121/1.3056564 